\title{
Design of Web Course Based on Cloud Computing
}

\author{
ZHENG NONG \\ College of Education Science \\ Guangxi University For Nationalities \\ Nanning,China \\ nongneal@163.com
}

\begin{abstract}
Cloud Computing Assisted Instructions (CCAI) bring new transformation and development for the web course. The paper introduces the characteristic, the design technique and the design method of the network course based on cloud computing and the network course is design combining with Google Apps and WEB.
\end{abstract}

Keywords- cloud computing; web course;system design of network curriculum; Google Apps

\section{INTRODUCTION}

All Cloud computing is usually referred to as the "cloud", is based on the internet related services with the increased use and delivery mode. From a technical perspective, cloud computing is a distributed computing, parallel computing, the utility computing, network storage, Virtualization, load balancing and the development of computer and network technology in traditional fusion product. In the clouds, all resources, including architecture, platform and software is passed as services -- users can use these resources by the "pay-per-use" model. So the cloud computing has advantages such as cost-saving, high availability, high scalability. The "service" and "pay-per-use" embodies the basic idea of cloud computing: All the services is provided to users with the form of lease.

\section{THE CHARACTERISTICS OF NETWORK CURRICULUM BASED ON CLOUD COMPUTING}

Network course based on cloud computing advocates platform on network curriculum construction and management in cloud computing, this advanced technology concepts of cloud computing is applied to the network curriculum, the cyber source is integrated into the cloud computing platform, and use the advantage of platform of collaborative learning, and use the advantage of platform of collaborative learning, reinforcement learning team consciousness, to form a good interaction, promote the occurrence of learning and communication. In order to improve the efficiency of network course learning, the learner to grasp knowledge required, make the learner master the required knowledge more effectively. Cloud computing is introduced into the network curriculum, is one of the most important educational application of cloud computing, which has remarkable characteristics ${ }^{[1]}[2]$.

\section{A. Low for cost}

Cloud computing can make reasonable allocation of resources, form a virtual resource pool with all infrastructure, the user can make use of resources according to need, and only have to pay on the part of the used resources, this approach can not only save cost, but also make full use of the resource scientifically and reasonably.

\section{B. Terminal for low}

Wide network interface, which support for multiple client, can make the computing resources into a virtual pool of resources, meet the various requirements of users in the form of leasing, such as mobile phone, palm computer and PDAS. All service resources are distributed in the cloud; merely a Web browser can make it possible to access and use the resources according to the needs of users.

\section{Highly sharing of resources}

The great virtue of cloud computing technology is the resource sharing. Teaching resources include teaching equipment, teaching files, teaching plan, teaching case, digital media, network courseware, digital library, computer room etc.. Cloud computing can be developed for teaching resources integration together, realize the sharing of resources.

\section{Cooperative communication}

With the help of open cloud computing platform, teachers and students can be real-time in network teaching space to publish their own experiences; students receive timely and effective feedback. At the same time, the students can actively participate in the teaching and improve the learning enthusiasm through the teaching activities of participation in management, online discussion of network.

\section{THE DESIGN OF THE WEB COURSE BASED ON CLOUD COMPUTING}

\section{A. The system requirements analysis}

Requirements analysis is an important process of the software engineering development; its aim is to completely and accurately describe the needs of the learners, to understand the changes of the needs for the learners in the learning process and dynamically to change with it, to make the consistent between system analysis and learners' needs. It is to ensure the application and efficiency of the system. The requirements analysis of the web course mainly includes three aspects, namely: learner, technical and operational. $^{[3]}$

1) The analysis of the learner

The analysis of the learner is mainly to understand the learner needs in the learning course, the motivation for learning and the personality differences, etc. It needs to 
analyze the learner's general characteristics, entry capacity and learning styles, etc. ${ }^{[4]}$

2) The analysis of the technology

The analysis of the technology is to make the system framework of the requirements analysis, including the characteristics analysis and learning content and learning objectives of the learners and the learner's requirements of operational rights (security); to make the feasibility analysis for developing software and technical and implementation processes, etc.

\section{3) The analysis of the operability}

The analysis of the operability is to provide the general approach of learner's requirement to collect, collate and be analysis. The characteristics of the learner's requirement is the progressive, increment and dynamic. Therefore, the system designer must be constantly, gradually in-depth exchanges the ideas with the user (the teacher and the students) in the requirements analysis process, and constantly digging, sorting, and get the most desired needs of the user. Moreover, it needs to constantly improve the system according to the learners' idea.

\section{B. The system design of the web course}

\section{1) The functional design of the system}

The cloud services and the database of network course system is researched, designed and developed by the instructional designers and the system developers.

For the function design, the cloud services of the teaching information system can set the following function modules: teaching database, network test database, teaching BBS, teaching courseware development, experimental teaching, the electronic learning file management, teaching evaluation, virtual classroom teaching, remote teaching, academic achievement, and system management etc. The various modules of the system are a variety of sharing and collaboration, the user get the teaching information and services by the Web or mobile phone and other mobile devices, so as to realize the maximum sharing.

For the application design, the system has the following functions :

a) Having the practical teaching function.

It includes teachers' curriculum making, upload resources, students learning, job management, network BBS, online questions and answering, students download curriculum resources, online testing, practical training, etc.

b) Using the most of teaching strategy.

To achieve the collaborative learning strategies from the modules of network BBS and online answering question. The students can be personalized learning, be online training and testing to understand the learning effectiveness according to the teachers providing courseware and teaching resources, so the students truly realize autonomous learning.

c) Taking the students as the center.

Network teaching system is the embodiment of the student-centered mode, providing personalized learning teaching platform, powerful, simple and practical, easy to operate.

d) Having a good function for management.
Network teaching platform should have the function of curriculum management, teacher management, student management, teaching management, and the other management, etc.

2) The structure design of the system

According to the system analysis, the construction of network curriculum should have the following several function modules and each module have a relatively independent structure and hierarchy, being convenient for the system's maintenance and update ${ }^{[5]}$.

a) The navigation system.

Learning navigation system to effectively guide the teaching process, help the choice of teaching content, teaching process and circuit, searching for required resources.

b) The intelligent learning system

Including course content, the content of extracurricular knowledge expansion, learning tool etc, and student can carry on selective learning to meet the personalized learning objective requirements.

c) The guidance and communication system

Learning instruction and communication systems include the online answering question of course BBS, QQ class, message board to meet learner's communication and collaborative learning.

d) The evaluation and feedback system

The learning evaluation and feedback system includes students' personal information, students' information, students' assessment information, etc, providing learning evaluation basis for teachers through network feedback, and helping update student content and the network system.

e) The resource management system

It includes a learning resource base, and the management and updating of the dynamic database.

The system logic structure is shown in figure 1 .

The learners can use the network course by logging in own account, accessing to the intelligent learning system to learn according to the needs of their learning with the help of learning navigation; accessing to each database of learning resource repository to query the required learning data according to the requirements of autonomous learning.

The system can provide the environment for learning exchange, carrying on online FAQ, class QQ, message and comments, etc.

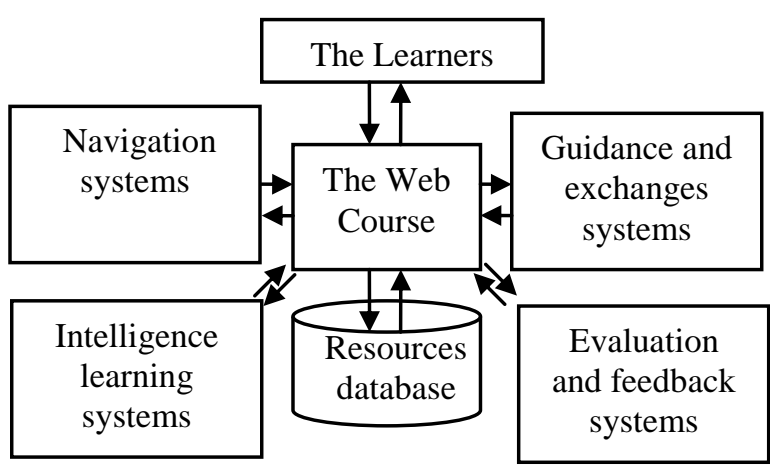

Figure 1 The network course system logic structure 


\section{3) Learning mode design}

Autonomous learning is an important learning way for the students; it can be shown in Figure 2 that the students use the network course to achieve autonomous learning

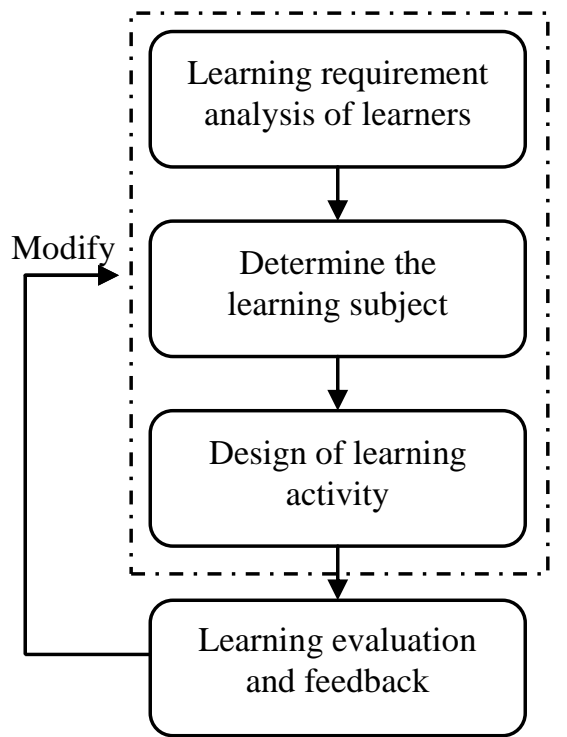

Figure 2 The learning mode of the course

Learning requirement analysis can help learners to understand the gap between their own knowledge, skill level and their expectation, to determine the starting point of learning, to prepare for reach learning expectations.

To determine the correct learning objectives can choose learning content, learning methods and learning resources and the final can be realization of learning objectives.

The design of learning activities is to form an organic system with the teachers, the learners, the content and the media. In the learning process, the learner is the main body and the teachers play a leading role.
The main purpose of teaching evaluation is to give feedback of implementation of the curriculum in the each link of the learning process, so as to realize the following up and adjustment of the course, finally promoting the effective construction of the web course.

The service design of cloud computing

Cloud computing provides three levels of service, namely: infrastructure as a service (IaaS), platform as a service $(\mathrm{PaaS})$, and software as a service (SaaS).

IaaS(Infrastructure-as-a Service). Consumers can gain perfect computer infrastructure service from the Internet. It can provide virtual hardware resources, such as hosts, storage, network resource; users can build their own application system from Internet leasing.

PaaS(Platform-as-a-Service).Building on the cloud infrastructure, it can provide application service platform for cloud application developers. PaaS actually take the platform of software development as a service, presenting to the user with the SaaS model. Therefore, the PaaS is an application of the SaaS model. However, the emergence of PaaS can speed up the development of SaaS, especially speed up the development of SaaS application.

SaaS(Software-as-a-service). All kinds of application service developed by the cloud platform, and according to specific needs to provide a complete application by multiple rented as a service. It is a model which needs Internet provide software, user do not need to buy the software, But to the provider renting the software based on Web, to manage the business activities of enterprises.

In the three services, IaaS (Infrastructure-as-a-Service) tend to be the universal service, SaaS (Software-as-a-Service) tend to be the special service and PaaS (Platform-as-aService) is the management service.

For the three types of services, It is well know that the cloud computing is not just in the software's application layer, it should also include hardware, software, or network, service and so on. The service of the web course base on cloud computing can adopt three layers of architecture, as shown in Figure $3^{[6]}$.

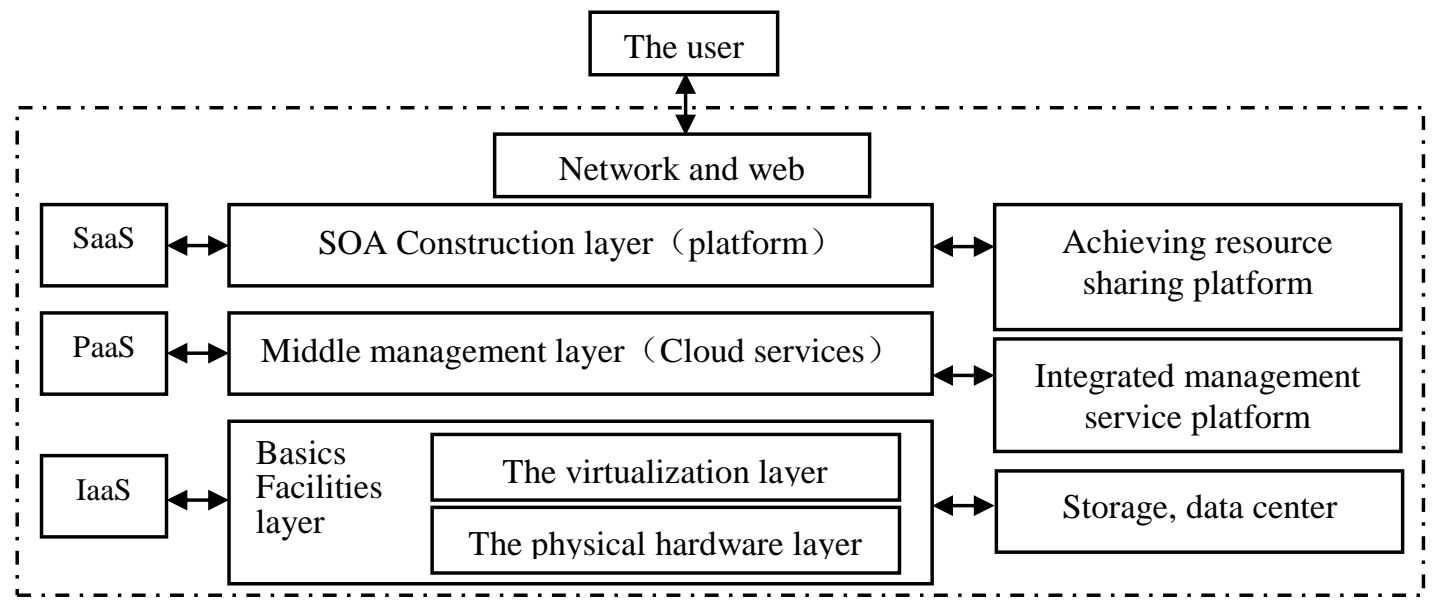

Figure 3 the service layers of cloud computing 
The top layer is the cloud application, it provides customers with services and solutions, this layer provides final network learning resources sharing application services which directly cater to the terminal, such as the teaching management system, knowledge management system, study and communication platform, operating system, document processing software, courseware and media presentation, virtual laboratory, and so on.

The outermost layer is the user side, it mainly installed with Web browser of personal computer, mobile phone, PHD, etc. All the network learning resources is released on the cloud sever in the form of "cloud", the user can access to learning resources as long as through terminals.

\section{The selection ofthe cloud platform software}

The choice of cloud computing and cloud platform software not only relates to the development and implementation of network course, but also related to the system's maintenance and update. At present, the main platform provide cloud computing are Amazon Elastic Compute Cloud (EC2), Google's Cloud Computing platform, IBM Blue Cloud, etc.

In terms of technology, we should consider the suit of cloud and the function of cloud services, cloud computing and WEB technology, cloud computing and media technology, etc, selecting the appropriate development platform.

Google Apps is a good platform for network course, rich in functional components, integrating all kinks of typical characteristic of Google service, including the following several features:

\section{1) Free of charge}

The standard version of Google Apps is completely free, and it provides relatively complete functions which can meet the user usual learning.

2) To open up

The openness of Google Apps is embodied by the Google's collaboration platform; the learners can also participate in the course of the construction, so that learners play a role more abundant.

\section{3) Shared}

The biggest characteristic of Google Apps is shared, it provides most services are based on sharing basis, such as documents, calendar etc. The sharing of document can realize the current learning tasks' common programming, and the sharing of calendar can help learners understand other learner's task arrangement.

\section{4) Collaboration}

Most of the services are provided by suit of Google Apps, which is in order to realize the cooperation for the members, so as to promote mutual exchanges and improve work efficiency.

\section{5) Personalization}

Google Apps supports the development of learner's individualized, the learners can create the own personalized web site, and it also can be shared, it also emphasizes communication and interaction while pay attention to individual character, making the learners' personality get a rational, scientific and effective development.

Google cloud services suite provides good technical support and free service for the construction of network teaching platform, Google sites is a free visualization service for web station, Google document can be free online, storing and sharing, Google Group is equivalent to BBS, Google calendar to be able to schedule reasonable management, Gmail is the free Google webmail service, Google can realize the teaching evaluation ${ }^{[7]}$

\section{CONCLUSION}

Base on the web, Cloud computing will mark the implementation of network socialization, it is also the big background, the environment of Web2.0 concept, it can be said that any Web application is an application of cloud computing, and all the Web 2 application is Cloud Computing ${ }^{[8]}$. Based on cloud computing, the web course system reduces the cost of hardware, software and management, achieve coordination, sharing, and have very high security. Enjoying the high quality service using portable equipment to be able to, "any time, any place", has become a new requirement for network service, Cloud computing will be in a wide range of applications, will greatly promote the reform and the development of education.

\section{ACKNOWLEDGMENT}

Supported by The Project of Education Science Planning of Guangxi China (No.2010C044 ).

\section{REFERENCES}

[1] Zhao Dan,Application Research of Online Curriculum Based on CloudComputing,Central China Normal University,Master's Degree Thesis ,pp:11-12,2012.

[2] WANG Ping,ZHANG Ji-ping,Cloud Computing and Network Learning,Modern Educational Technology.pp:81-84, November 2008.

[3] NONG Zheng .Design and Application of Network-course Based on Autonomous Learning.Modern Educational Technology.Vol. 21,PP:95-99, December 2011.

[4] Sharon E. Smaldino,James D.Russell,Robert Heinich,Michael Molenda . INSTRUCTIONAL TECHNOLOGY AND MEDIA FOR LEARNING [Eighth Edition].Beijing:HigherEducation Press. PP:48. 2005.

[5] NONG Zheng,Design and Application of Multimedia Network Course based on Web, ICCSN 2011,VOL.1,pp:177-181

[6] HOU xiaofan,The Crawler of Education In Web By Cloud Computing, Northeast Normal University ,Master's Degree Thesis,pp:6-9,2011.

[7] LI weiying ,Multimedia TechnologyCourse Design and Practice Based on Cloud Computing Environment, Value Engineering.pp:144-145, 2011(25).

[8] LI fangfang.Educational Website Construction Based on Web2.0 in China.Software Guide ,PP:77-79, November 2009. 